\title{
Estrogen and learning: Strategy over parsimony
}

\author{
Tracey J. Shors \\ Department of Psychology, Center for Collaborative Neuroscience, Rutgers University, Piscataway, New Jersey 08854, USA
}

In the current issue of Learning \& Memory, McElroy and Korol (2005) present novel findings with respect to estrogen and learning, indicating how fluctuating levels of estrogen might alter strategies that rats use in order to obtain rewards. Specifically, they show that female rats with enhanced but nonetheless physiological levels of estrogen prefer strategies that capitalize on visual cues in space to find a reward, whereas those with low levels of estrogen prefer strategies that capitalize on behavioral responses that were effective previously and thus led to the reward. Importantly, for all manipulations, there was no real effect on learning per se but rather just a change in the type of strategy that a given rat used. In addition, McElroy and Korol (2005) were able to manipulate these preferences by altering the level of synaptic inhibition in the hippocampus, and in fact could make an animal that used one strategy in the presence of high levels of estrogen switch to the alternative strategy. To me, these results are noteworthy for several reasons: one because they are unambiguous, two because they are robust (as distinct from unambiguous), three because they refer to levels of estrogen experienced by living females in the known universe, and finally because they are potentially informative about how estrogen alters behavioral and cognitive processes that may be involved in learning. Minimally, these results force us to consider estrogen modulation from a different perspective. I will address each in turn.

First-the unambiguous part. As those of you who follow this literature are well aware, it is confusing and the results are inconsistent at best. There are reports that estrogen can enhance learning, reports that it can impair learning, and reports with no effect whatsoever-all from my lab alone (Fig. 1). This is not to say that the results are inaccurate as reported, but rather that estrogen's effects are many and certainly not confined by human notions of good and bad. That said, the results from McElroy and Korol (2005) are unambiguous-as estrogen levels decrease from proestrus to estrus, the likelihood of using a place strategy decreases from $\sim 65 \%$ to less than half of that $(28 \%)$. Meanwhile, as estrogen levels increase from estrus to proestrus, the use of the response strategy decreases from $\sim 75 \%$ to less than half of that (33\%). Exactly why this would occur is yet unknown, but such a reversal suggests some fundamental change in responses to environmental events as estrogen levels rise and fall.

Now let me address the second point, that of robustness. Probably the most worrisome aspect of the estrogen and learning literature is the meager effects that are often reported. Suffice to say, the effects reported by McElroy and Korol (2005) are robust, including those in response to hippocampal inhibition. The females in proestrus are probably most illustrious, since they demonstrate the most dramatic switch in choice as their hippocampus is inhibited. There does seem to be something particularly malleable about females in proestrus and how they respond to the world around them. In our studies, we have

E-mail shors@rci.rutgers.edu; fax (732) 445-2263. Article and publication are at http://www.learnmem.org/cgi/doi/10.1101/ Im.93305. shown that females in proestrus classically condition more than females in any other stage (Fig. 1A; Shors et al. 1998), but they are also most sensitive to stress and thus show the largest deficit in conditioning in response to a stressor (Fig. 1B; Wood et al. 2001; Leuner et al. 2004b). Why females in proestrus are so sensitive to environmental change is still an open question, but it may be that they are especially sensitive to changes in synaptic inhibition, as demonstrated here and in recent studies by Woolley and colleagues (Rudick and Woolley 2001).

The third point and the one that keeps me up at night is estrogen concentration. Of the many studies reported in the literature, I would guesstimate that more than $90 \%$ do not measure endogenous hormone levels, making it impossible to determine how much estrogen is being experienced by the female at the time of testing. Also, in many cases, estrogen concentrations would be and indeed are very high, not physiological, and thus irrelevant to female life. We recently tested whether exogenous exposure to estrogen in ovariectimized females would enhance learning, in this case of a classically conditioned eyeblink response (Leuner et al. 2004b). We found no effect on performance at any dose that would be experienced by a female under normal living conditions (Fig. 1C). However, we did find enhancing effects at very high doses, nearly $10 \times$ what a female rat in proestrus (when estrogen levels peak) would experience. What does that say about estrogen in living breathing females? Not much. It probably does say something about learning in women treated with estrogen after menopause or hysterectomy, many of whom are prescribed supraphysiological doses of "replacement therapy." But if we are to understand the effects of estrogen in the female as she lives, it must be done with physiological doses of estrogen, preferably with the cycle intact.

For the final and most important point-why are these findings novel and important? For the last ten years or so, there has been a significant increase in studies on estrogen and learning, and this is certainly a welcome change. However, there are many assumptions about estrogen and learning that are probably just wrong. Certainly, it cannot be the case that estrogen would have some kind of all-or-none effect on learning, since half of the human population would be in serious trouble most of the time. Thus, it must be the case that estrogen "modulates" learning to some extent at one time versus another without affecting overall learning ability. But "modulation" is not very satisfying as a way of explanation. If the current data can be generalized, then it would seem that estrogen alters preferences for using one strategy versus another. Now this does make sense and is somehow satisfying. Stages of estrus probably evolved in order to facilitate survival of the young by spacing births according to species and environmental constraints. These stages are expressed as behaviors that ensure survival of the mother, her offspring, and the species. With an inhibited hippocampus, the animal may resort to the easier although presumably less adaptive response strategy. Of course, we can never know whether a strategy evolved for a specific reason, but results like these increase my appreciation for strategy over parsimony. 


\section{Acknowledgments}

This work was supported by NIH (MH 59970).

\section{References}

Leuner, B., Mendolia, S., and Shors, T.J. 2004a. High levels of estrogen enhance associative learning in the female rat.

Psychoneuroendocrinology 29: 883-890.

. 2004b. Males and females respond differently to controllability and antidepressant treatment. Biol. Psychiatry 56: 964-970.

McElroy, M.W. and Korol, D.L. 2005. Intrahippocampal muscimol shifts learning strategy in gonadally intact young adult female rats. Learn. Mem. (this issue).

Rudick, C.N. and Woolley, C.S. 2001. Estrogen regulates functional inhibition of hippocampal CA1 pyramidal cells in the adult female rat. J. Neurosci. 21: 6532-6543.

Shors, T.J., Lewczyk, C., Mathew, P., Paczynski, M., and Pickett J. 1998. Stages of estrus mediate the stress-induced impairment of classical conditioning in females. Neuroreport 9: 419-423.

Wood, G.E., Beylin, A., and Shors, T.J. 2001. The contribution of adrenal and reproductive hormones to the opposing effects of stress on trace conditioning in males versus females. Behav. Neurosci. 115: $175-187$.
A Learning increases

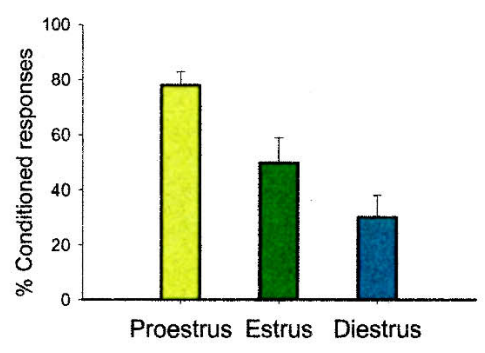

B Learning decreases

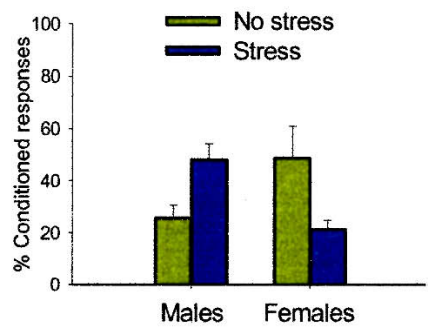

\section{No change in physiological range}
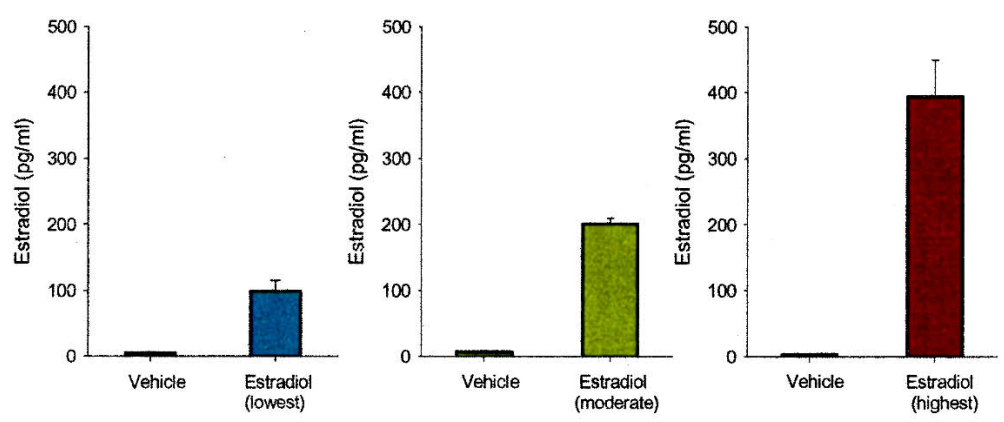

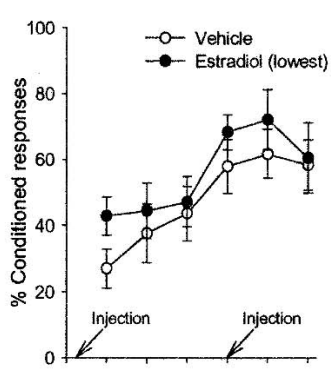

100200300400500600

Trials

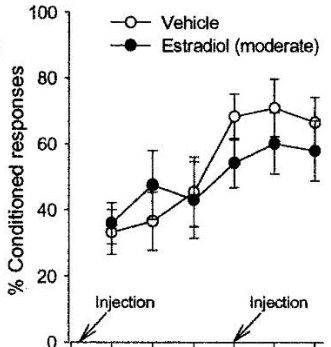

100200300400500600

Trials

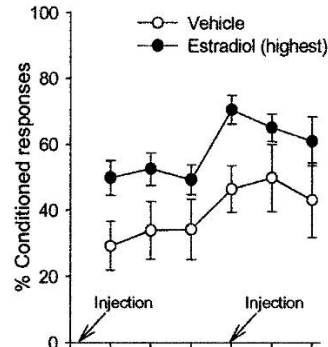

100200300400500600

Trials

Figure 1. Examples of estrogen effects on processes involved in learning, and how estrogen can modify learned responses in very different ways. ( $A$ ) The percentage of conditioned responses in female rats during three stages of estrous: proestrus, when estrogen levels are elevated, estrus when they are low, and diestrus, when they are also relatively low. Females in proestrus outperform females in other stages, at least as measured here during classical eyeblink conditioning with a delay-type paradigm (Shors et al. 1998). (B) How stressful experience affects classical conditioning differently in males vs. females and does so especially in females trained during proestrus, when estrogen levels are relatively high (Wood et al. 2001). The data are the percentage of conditioned responses, this time using the hippocampal-dependent task of trace eyeblink conditioning. Males and females were exposed to an acute stressor or not and then trained $24 \mathrm{~h}$ later. The final set of graphs $(C)$ shows that physiological levels of estrogen do not necessarily alter learned responses (Leuner et al. 2004a). In these experiments, female rats were ovariectomized and given estradiol by injection. Trace conditioning was affected only at the highest concentration, one that is not physiological but can be experienced by women during replacement therapy. 


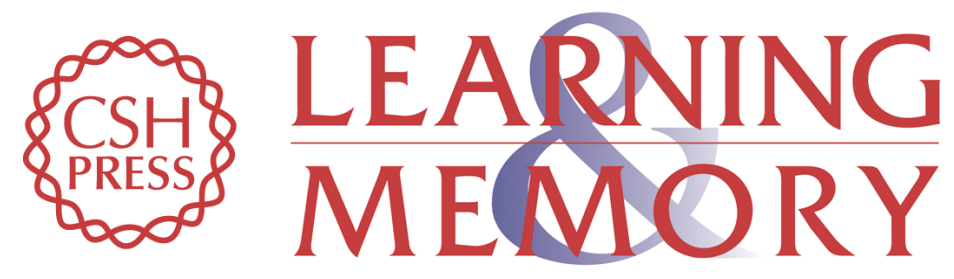

\section{Estrogen and learning: Strategy over parsimony}

Tracey J. Shors

Learn. Mem. 2005, 12:

Access the most recent version at doi:10.1101/lm.93305

References This article cites 5 articles, 1 of which can be accessed free at: http://learnmem.cshlp.org/content/12/2/84.full.html\#ref-list-1

License

Email Alerting Receive free email alerts when new articles cite this article - sign up in the box at the Service top right corner of the article or click here. 